Gutiérrez, José Ismael, Dos acercamientos a un motivo literario de fin de siglo: La "Salomé" de

Oscar Wilde y la de Enrique Gómez Carrillo , Hispanic Review, 63:3 (1995:Summer) p.411

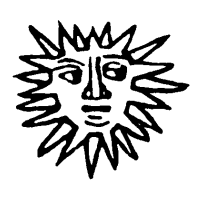

\title{
DOS ACERCAMIENTOS A UN MOTIVO LITERARIO DE FIN DE SIGLO: LA SALOMÉ DE OSCAR WILDE Y LA DE ENRIQUE GÓMEZ CARRILLO
}

\author{
José Ismael GutiérREz \\ Universidad de La Laguna
}

La violencia de la que la muerte está penetrada nos induce a la tentación más que en un sentido, si se trata de encarnarla en nosotros contra un vivo, si nos posee el deseo de matar. Georges Bataille

\section{I}

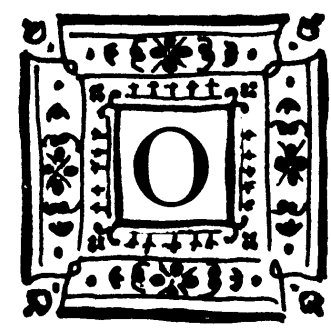

SCAR WILDE (1854-1900) terminó de escribir (en francés) su Salomé a principios de 1892; la obra se publicó en 1893, y su versión inglesa un año más tarde. Enrique Gómez Carrillo (18731927) publicó en 1898 por primera vez "El triunfo de Salomé" como una de las piezas incluidas, según ha investigado Marini-Palmieri, en el volumen Del amor, del dolor y del vicio. ${ }^{1}$ El primero de los textos es

\footnotetext{
${ }^{1}$ El crítico paraguayo nos informa de que "El relato figura, según fuentes bibliográficas como la Unión de Bibliotecas Norteamericanas (NUC), por primera vez en una edición parisiense de la Editorial La Campaña, en 1898, de Del amor, del dolor y del vicio" (101). El dato necesita ser comprobado. Consistiendo dicha obra en un texto novelesco, es poco probable que Gómez Carrillo introdujera en el mismo libro un relato breve. ¿Se trata de un despiste del crítico o, por el contrario, nuestro escritor efectivamente publicó junto con la novela algunas de sus piezas cuentísticas, entre las que estaría “El triunfo de Salomé?" Hasta la fecha ignoramos la respuesta. De todas maneras, al no haber podido acceder a la primera edición de Del amor, del dolor y del vicio nos atenemos a lo indicado por Marini-Palmieri, por ser ésta la única referencia bibliográfica que, por ahora, se halla a nuestra disposición.
} 
una obra teatral: más concretamente, un drama; el segundo es un cuento modernista que abarca apenas unas cuantas páginas. Las concepciones de ambas producciones literarias, según veremos, no pueden ser más divergentes. Sin embargo, un nexo común las une: el interés por la figura bíblica de Salomé, hija de Herodías y sobrina de Herodes Antipas. A esta coincidencia habría que agregar una circunstancia extraliteraria: la relación del escritor irlandés con el cronista guatemalteco. La base de este parentesco no sólo radica en la contemporaneidad de las dos obras, gestadas durante la década del 90 del siglo pasado, sino que disponemos asimismo de un dato de tipo biográfico que nos presenta a ambos escritores comiendo y bebiendo juntos, dialogando, intercambiando opiniones, etc. en el París de 1891. En ese año Oscar Wilde viajó hasta Francia, donde realizó una larga estancia que le permitió ponerse al día en asuntos literarios y relacionarse con los poetas y artistas franceses de última hora. Asiduo de los cafés parisinos, no fue raro que se encontrara en uno de ellos (el Café d'Hartcourt) con Enrique Gómez Carrillo, al que acompañaba, en esta ocasión, Paul Verlaine. El encuentro puede datarse, según refiere Yvanhoe Rambosson y recoge Richard Ellmann en su monumental biografía sobre el escritor irlandés, en noviembre de 1891 (398).

$\mathrm{Al}$ poco de conocerse y pese a las diferencias que los separaban, entre Wilde y el autor de la Grecia eterna surge una pasajera pero cordial amistad, que más tarde Gómez Carrillo evocaría en su libro En plena bohemia (1919), así como en el Prólogo que escribió para la edición española de Salomé (de 1901 ó 1902), titulado "El origen de la 'Salomé' de Wilde."2 El biógrafo norteamericano Richard Ellmann sugiere que la reunión en el Café d'Hartcourt a la que nos hemos referido, y en la que Wilde brilló, como siempre, por su ingenio en el arte de la conversación relatando su vida, sus viajes, su amor a la existencia y a las sensaciones, etc., sea tal vez el primer

\footnotetext{
2 También en su primer libro Esquisses, aparecido en Madrid en 1892, traza la silueta literaria de Wilde, además de la de otros escritores que estaban en el candelero (Amado Nervo, Paul Verlaine, Alejandro Sawa, Charles Maurras, Rubén Darío, etc.). La amistad con Wilde se extendería casi hasta la muerte del autor de Salomé. Hacia 1900, si la memoria de Rubén Darío no falla, se vieron en París. Era el año de la Exposición Universal. Rememora el poeta de Prosas profanas el día en que Carrillo y su amigo Ernesto Lejeunesse le presentaron en un bar llamado Calisaya a "un caballero un tanto robusto, afeitado, con algo de abacial, muy fino de trato y que hablaba el francés con un marcado acento de ultratumba" (130).
} 
contacto personal de Wilde con Gómez Carrillo (398); sin embargo, es posible que se conocieran antes, según se desprende de la edición de 1898 del libro Almas y cerebros, en el que figura un texto fechado en 1890 con el título de "Una visita a Oscar Wilde."

Gómez Carrillo se convirtió para Wilde en uno de sus confidentes. Estando a solas, el esteticista irlandés criticó la apariencia desaliñada de Verlaine: "El primer deber de un hombre es ser hermoso, ¿no cree usted?," a lo que Gómez le respondió: "Las únicas bellezas que conozco son las mujeres." Wilde, haciéndose eco del discurso decimonónico de la misoginia (y que en su caso dará paso a la homosexualidad), no estuvo de acuerdo con la observación de su amigo: “¿Cómo puede usted decir eso? Las mujeres no son hermosas en absoluto. Son alguna otra cosa, lo admito: magníficas cuando se visten con buen gusto y se cubren de joyas, pero no hermosas. La belleza refleja el alma" (Ellmann 398). Cuenta Ellman que Wilde le reprochó a Gómez que estuviese muy a menudo con cierta mujer. El escritor guatemalteco respondió, sin lograr atenuar en absoluto el reproche de su interlocutor, explicando que estaba enamorado de ella (398). A su vez, a la mujer en cuestión tampoco le caían muy bien los ademanes y actitudes de tan extravagante personaje, ya que al referirse a él lo tachaba de pederasta. Pero Gómez Carrillo hizo caso omiso a tales comentarios: le resultaban simpáticas las ingeniosas ocurrencias de su nuevo amigo y se sentía a gusto en su compañía. ${ }^{3}$

Posiblemente por entonces Wilde le transmitió a Gómez Carrillo su proyecto de hacer una obra sobre Salomé. En realidad, tanto le obsesionaba el tema que todos los días y a todo el mundo hablaba de lo mismo, de la Salomé que iba modelando en su cabeza y en la que hacía cristalizar, según los momentos, las más disímiles y aun contradictorias interpretaciones, por muy alejadas que éstas estuviesen de la realidad o de la verdad histórica. Su imaginación rebosaba de imágenes. Una noche en una cena en casa de Stuart Merrill, el poco atractivo Rémy de Gourmont interrumpió las fan-

\footnotetext{
${ }^{3}$ La afinidad de puntos de vista estéticos, que en lo que se refiere a Wildeindiferente a la división arte-vida - se hacían bien ostensibles en su misma persona, favoreció aún más la cálida amistad entre ambos escritores. Por eso un crítico como Luis Alberto Sánchez no se extraña de la admiración que despertó en Gómez Carrillo el visitante extranjero: "Seducían a Gómez Carrillo los aspectos vistosos y exóticos de la literatura. Era natural que Wilde, con su dandysmo y sus paradojas, ejerciera inevitable señuelo sobre él" (209).
} 
tasías de Wilde, aclarando: "Usted ha confundido dos Salomés. Una era la hija de Herodes, pero, como atestigua Josefo, no tenía nada que ver con la bailarina de la Biblia." Luego Wilde le comentó a Gómez Carrillo, que también estaba presente: "Este pobre Gourtmont cree que sabe más que nadie. Lo que nos dijo era la verdad de un profesor de instituto. Yo prefiero la otra verdad, la mía, que es la de los sueños. Entre dos verdades, la más falsa es la más verdadera" (Ellmann 399).

Otra velada, que sintetiza Ellmann, tiene lugar en casa de Jean Lorrain, con Marcel Schwob, Anatole France, Henry Bauer y Gómez Carrillo como invitados. Pidió ver un busto de una mujer decapitada del que había oído hablar. Mientras examinaba las manchas de sangre pintadas en el cuello sobre el lugar donde la espada había cortado, gritó: “iEs la cabeza de Salomé; Salomé, que se hizo decapitar por desesperación! Es la venganza de San Juan Bautista." Y para explicar este insólito desenlace, no recogido en ninguno de los textos antiguos que se han ocupado de la leyenda, pasa a referir una historia apócrifa sobre lo que sucedió realmente después de la muerte de Juan Bautista. Ante el carácter asombrosamente imaginativo de las divagaciones de Wilde, Lorrain no pudo por menos que decirle: "Está escribiendo usted un singular poema" (Ellmann 399-400).

\section{II}

Pero ¿por qué Salomé el motivo elegido? En primer lugar, hay que señalar que tal propuesta en los medios finiseculares apenas goza de originalidad. La atracción por Salomé en tanto figura de dimensiones humanas trágicas, complejas y tan poéticas que la hacían digna de ser representada literariamente, no era exclusiva de Wilde, ni mucho menos de Gómez Carrillo. Sin lugar a dudas, había un ambiente cultural generalizado que propiciaba su temática, que adoptó sin reservas: la imagen de la mujer seductora, en la que se alinean belleza y mal, perversión y buenas dosis de crueldad, que interpreta con sensualismo una danza casi orgiástica capaz de despertar los más ardientes deseos sexuales entre quienes la miran, era un arquetipo femenino, entre otros muchos, que vehiculizaba varias de las obsesiones que inquietaban a los artistas finiseculares. Muchos autores de la época quedaron atrapados entre sus velos. No en vano Flaubert, Mallarmé, Laforgue, Lorrain, Ana- 
tole France y Eugenio de Castro le rindieron fervoroso homenaje, sin olvidarnos de las versiones de Carlos Arro y Arro, Goy de Silva o Gerónimo Zanné en España, así como del cuento que dedicó el hondureño Froylán Turcios al mito, o el soneto descriptivo del poeta cubano Julián del Casal, por sólo citar dos ejemplos tomados de las letras hispanoamericanas. ${ }^{4}$

Pero, además, el tema de la princesa hebrea que pide como recompensa por su danza, a instancias de su madre, la cabeza de San Juan Bautista, no sólo causó furor en los medios literarios; también la iconografía de las artes plásticas aparece dominada por la misma fascinación. Y es digno de ver cómo, igual que sucede en la literatura, también en la pintura de finales del siglo XIX se aprecia un cambio de enfoque, aunque originado algún tiempo atrás. ${ }^{5}$ Como ha comentado Erika Bornay, "a pesar de que en la historia de la pintura el sugestivo personaje de Salomé captó a través de los siglos el interés de numerosos pintores (Giotto, Botticelli, Lippi, Van der Weyden, Cranach, Alonso Berruguete, Caravaggio, Reni, Rubens, entre los más famosos), ninguno de ellos se aproximó a su figura con la lúbrica mirada de los artistas fin-de-siècle, quienes, proyectando en la joven hija de Herodías su especial sensibilidad, iban a recrearla, haciendo de ella el summum de las perversidades, seducciones y poder letal" (188-89). (Moreau, el dibujante inglés Aubrey Beardsley en sus ilustraciones para la edición inglesa de la obra teatral de Wilde, Puvis de Chavannes, etc. no escaparon a su influjo).

No es de extrañar que en una época que tanto gustó de las "flores del mal" (según la poetización que de las mismas hizo Baudelaire)

\footnotetext{
${ }^{4}$ Un estudio sobre la presencia de la hija de Herodías en la literatura, editado en 1919, fue el llevado a cabo por Cansinos Asséns, lo que demuestra que ya por entonces se tenía una temprana conciencia de la enorme aceptación del tema en el ámbito de la creación literaria.

${ }^{5}$ Erika Bornay menciona un grabado realizado en 1779 por Henry Fuseli para la edición inglesa de los estudios de fisonomía de Lavater, titulado La hija de Herodías con la cabeza de San Juan, "en el que una Salomé de provocativo gesto adquiere toda la apariencia de aquellas bacantes, prostitutas y cortesanas que tan a menudo aparecen en la obra de este artista" (Bornay 189). En el ámbito literario Mario Praz recuerda que fue Heinrich Heine, en Atta Troll (escrito en 1841), el que introdujo, antes que Huysmans, Flaubert o Wilde, el motivo derivado de una tradición popular alemana (315), sólo que en este poema, añadiremos, el escritor germano traspasa todos los atributos y características de la bailarina a su madre Herodías, desesperada de amor por al profeta hebreo.
} 
se hiciese tan popular el tópico. Lily Litvak, que ha rastreado las huellas de Salomé en la literatura española (desde 1880 a 1913), descifra el significado del mito en los siguientes términos:

Representaba una mezcla satánica de belleza ultrarrefinada, voluptuosidad, crueldad y astucia. Era la clásica personificación de la decadencia, en la que se unían todos los motivos queridos a esta mentalidad: esteticismo, localización en un pasado que superaba con su crueldad y sus vicios la trivialidad del presente, el pecado cometido como obra artística. Significaba también la fatal sujeción a las pasiones que hacían llevar la vida en un plano diferente del vulgar lugar común. El erotismo se presentaba en todo tipo de formas anormales: pasión senil de Herodes por la princesa, ímpetu sexual de ésta por San Juan. Las aspiraciones sexuales permanecen allí cohibidas en su desarrollo por un velo ético o social; diferencia de jerarquía, afinidad consanguínea, voto del nazareno. Siempre pasiones condenadas a permanecer latentes en forma de angustia sexual, de aberración estéril capaz de satisfacerse tan sólo mediante el crimen.

Como vemos, la alteración que se opera en la vieja imagen de la princesa de que nos hablan los Evangelios de San Mateo y San Marcos, así como el historiador profano Flavio Josefo-y sobre todo el protagonismo que la misma adquiere dentro de un contexto histórico y cultural moderno-es bastante obvia. Salomé, de simbolizar la adolescente dotada de un candor extraño e inquietante, a la vez que de una pureza feroz, virgen indecisa, ejecutora de la voz materna, pasa a encarnar entonces, en la pluma de los escritores de fin de siglo, al arquetipo (o como prefiere llamarlo Hans Mayer, fenotipo $^{6}$ de la mujer fatal. ${ }^{7}$

\footnotetext{
${ }^{6}$ En su libro Historia maldita de la literatura el crítico alemán Hans Mayer utiliza el término en el capítulo "Dalila como vamp burguesa" (119-37).

${ }^{7}$ Un itinerario histórico sintético, desde sus orígenes bíblicos hasta sus derivaciones simbolistas y decadentes, de la femme fatale, cuyos referentes literarios habían sido estudiados magistralmente por M. Praz en su aún no superado libro, lo encontramos trazado en El reino interior de Giovanni Allegra: "El mito de la mujer cruel y altanera, disoluta y sanguinaria había comenzado con Lilith, mujer y demonio bíblico, seguiría con las Ménades, Sirenas, Gorgonas, después con las Cleopatra y Mesalina históricas, las más cercanas Lucrecia Borgia y condesa de Challant, hasta las diversas Carmen que los exotismos románticos concibieron y llamaron con nombres distintos. Pero sólo con los decadentes-continúa el crítico italiano-llega este mito a ser sentido, poetizado y fijado en la iconografía con tanta intensidad que marca por sí solo un momento preciso en la historia de la moda literaria y del gusto. Con Salammbô de Flaubert comienza a adquirir sus decisivos contornos sanguinarios en los que se funden exotismo y erotismo para crear a la
} 
Importancia difusora en la reactualizada visión de Salomé, tal como la concibió la sensibilidad de la época, tuvieron las dos descripciones que en $\dot{A}$ Rebours (1884), de J. K. Huysmans, se hace de dos cuadros de Gustave Moreau (la Salomé danzante y La aparición), los cuales serían en parte elementos inspiradores de uno de los poemas parnasianos que Julián del Casal incluiría en su libro Nieve (1891). ${ }^{8}$ Las pinturas de Moreau se caracterizaban por su atmósfera de misterio y sensualidad, por la aglutinación de símbolos extraídos de religiones y cultos diferentes. Eran creaciones hieráticas, bárbaras, casi siempre ambiguas. ${ }^{9}$ Fantasías bíblicas y mitológicas que se traducían al lenguaje visual de manera preciosista y enjoyada. Observa el narrador de la novela de Huysmans en el Capítulo v que Salomé:

ya no era unicamente la bailarina provocativa que logra despertar en un anciano el deseo y la apetencia sexual con las disolutas contorsiones de su cuerpo; que consigue doblegar el ánimo y disolver la voluntad de un rey balanceando los pechos, moviendo frenéticamente los muslos, sino que se convertía, de alguna manera, en la deidad simbólica de la indestructible Lujuria, escogida entre todos por la catalepsia que le tensa las carnes y le endurece los músculos; en la Bestia monstruosa, indiferente, irresponsable, insensible, que corrompe, del mismo modo que la antigua Helena, todo lo que se le acerca, todo lo que la mira, todo lo que ella toca.

En la obra de Moreau, el extravagante personaje de $\grave{A}$ Rebours, Des Esseintes, veía realizada la estampa inédita de una Salomé que, adornada con nuevos aditamentos tanto externos, aparienciales, como psicológicos, marcaba diferencias sustanciosas con los

vez un género que llegará a su cima en la Hérodiade de Mallarmé, en la Proserpina de Swinburne, en la Basiliola de D'Annuncio" (90).

${ }^{8}$ La sección "Mi museo ideal" de Nieve, dedicada a Gustave Moreau, está integrada por diez sonetos inspirados en otros tantos cuadros del pintor francés. Casal también se basó en las reproducciones en blanco y negro que conocía de la obra pictórica del artista francés, con quien, dicho sea de paso, mantuvo contacto epistolar.

${ }^{9}$ Refiriéndose a la ambigüedad en las figuras de Moreau, M. Praz ha expresado que "casi no se distingue en el primer momento cuál de los dos amantes es el hombre y cuál la mujer; todos los personajes están unidos por sutiles vínculos de parentesco como en la Lesbia Brandon, de Swinburne: los amantes tienen rostros virginales, las vírgenes, rostros de efebos; los símbolos del Bien y del Mal se enlazan y se confunden equívocamente. No hay contraste alguno de edades, de sexos, de tipos: el sentido secreto de esta pintura es el incesto, la figura exaltada es el andrógino, y la última palabra es esterilidad" (307). 
testimonios suministrados por el Nuevo Testamento y por escritores $\mathrm{y}$ artistas del pasado.

\section{III}

Esa misma lectura de la novela de Huysmans que inspiraría al mencionado Julián del Casal su soneto "Salomé," sirvió de base en cierta medida, así sea a un nivel accesorio, a la obra homónima de Wilde. También se ha barajado otro estímulo: la cita que en el capítulo decimocuarto de la misma novela se hace del poema "Hérodiade" de Mallarmé, por entonces inacabado e inédito hasta 1898, pero al que Huysmans accedió sólo fragmentariamente a través de un precioso manuscrito con versos del hermético poeta. Seguramente en las conversaciones que mantuvo Wilde con Mallarmé en 1891 debió salir a relucir el tema cuyo interés ambos compartían, si bien debemos aclarar en favor de Wilde que la curiosidad del irlandés por la leyenda de Salomé es anterior a sus reuniones con el poeta simbolista. De hecho, sabemos que al menos desde 1890 venía anunciando ya su intención de dedicarse al proyecto. Lo que aún no tenía decidido es el género literario que emplearía. Según Gómez Carrillo, en un principio Wilde no tenía en mente escribir una obra de teatro. Primero esbozó unas páginas en prosa, luego abandonó el trabajo; entonces decidió escribir un poema. Sólo más tarde, después de varios intentos fallidos, comprendió que lo más adecuado era la forma teatral (Ellmann 400). La idea de que Sarah Bernhardt la representase quizás lo indujo a escribirla en una lengua que, aunque no dominaba en profundidad, sí conocía lo suficientemente bien. Esa podría ser una de las razones, no la única. Lo cierto es que Wilde se divertía dando explicaciones diferentes como respuesta a una misma pregunta, de modo que, lejos de venir a despejar cualquier posible duda, contribuía aún más a aumentarla, despistando así al crítico de turno, al reportero que lo entrevistaba o, en todo caso, al interlocutor amigo, que tenía que interpretar pensamientos cuya nota sobresaliente era por lo común la vaguedad, la paradoja. Lo que está claro es que escribir en francés-un instrumento distinto pero que había escuchado toda su vida y con el que intentaría crear algo hermoso-suponía una experiencia nueva, según confesó a Robert Ross (Ellman 431). En otra ocasión declararía a un representante de Le Gaulois que apreciaba el idioma francés por su abierto aliento artístico y porque le 
permitía una libertad expresiva que la lengua y el público ingleses no toleraban: "Para mí sólo hay dos lenguas en el mundo: el francés y el griego. Aquí [en Inglaterra] la gente es esencialmente antiartística y de mente estrecha. Aunque tengo amigos ingleses, no me gustan los ingleses en general. Hay mucha hipocresía en Inglaterra, que vosotros en Francia, muy justificadamente, halláis criticable" (Ellmann 432).

Mucho de ese sentido artístico volcaría Wilde en una obra dramática que para Mario Praz parodia todo el movimiento decadentista (318); decadentismo cuya desaparición, por lo demás, Wilde había señalado en su diálogo "La decadencia de la mentira" (1888). Praz incluso, sin llegar a desarrollar una explicación que fundamente sus observaciones, va aún más lejos al afirmar la existencia de un humorismo, tal vez deliberado, en la concepción dramática de la obra. Sin llegar a esos extremos, el escritor irlandés acumula, es cierto, una serie de lugares comunes que reconoceremos fácilmente en otros escritores del momento. Podemos constatarlo. Ahora bien, el carácter pretendidamente "humorístico" del texto wildeano, en sentido estricto y literal, no se hace perceptible. ¿Se refería acaso Praz a la demanda de lujo, al exotismo o a la intensa tragicidad que impregna la atmósfera del drama? Si es así, esos y otros excesos quedan muy bien equilibrados ante la concisión de unos diálogos escénicos en los que nada parece faltar y en los que apenas nada sobra. A ello contribuyen, sin lugar a dudas, una prosa de remansos bíblicos y unos silencios cargados de mensajes (tan significativo es lo que se dice como lo que se calla). Las palabras aparecen imantadas así de una oculta energía ritual. "Salomé-diría Luis Antonio de Villena-es un drama de máscaras (los actores parecerían hablar sin mirarse, sin saberse) y desde luego, de alucinación y rito" (76). No es necesario entonces recurrir a la parodia para valorar la Salomé de Wilde, ni es necesario dirigir la vista al blanco que nos parece más fácil (su carácter de "obra especiosa de segunda mano," como la califica Praz [318]) para enumerar sus múltiples defectos, que son también los defectos de la estética exotista y recargadamente simbólica de finales del siglo XIX.

Cuando Wilde planea su obra, lo hace sólo pensando en la exposición de una pasión perversa, destructora: la pasión amorosa que destruye aquello que no se puede poseer. Wilde era de los que creían que se mata aquello que se quiere. Y en cierta medida no pudo evitar que ese negativismo vital-progresivo conforme avan- 
zaba el tiempo-se colara en su obra literaria, como tampoco pudo evitar el sentirse fuertemente identificado con un mito legendario que materializaba tal convicción. Para lograr su objetivo Wilde modificó a su antojo el relato originario, haciendo que la bailarina, después de danzar ante Herodes, pidiese la cabeza de Iokanaán, no para obedecer a su madre, sino por un amor no correspondido. Ese pequeño cambio introducido por Wilde en las motivaciones y conductas tradicionalmente asociadas a los personajes de la leyenda, es más significativo de lo que parece a simple vista, porque, por un lado, transforma la decapitación del profeta en un acto de venganza personal: es la joven que baila, no su madre, la que exige la cabeza del hombre al que ama. Nadie lo sabe, pero es así. Por otro lado, la transferencia del móvil de la madre a la hija también acentúa la tensión dramática que empieza a consolidarse desde el principio de la trama. El silencio se vuelve premonición. Señales de mal augurio, elementos funestos (el color cambiante de la luna, la palidez de la princesa, la sangre derramada en el suelo, el batir de alas que percibe Herodes) intuyen, a ojos de algunos personajes, un trágico destino. El fatalismo, desde la primera mención a la luna amarillenta hasta la decapitación de Iokanaán, que cierra el climax, se cierne por completo sobre un marco escénico-decorativo urdido de acuerdo con el gusto exotista de la época. Se evoca así un Oriente fabuloso repleto de riqueza, gemas, aves exóticas y objetos con poderes mágicos (el derroche de rarezas culmina en la enumeración de los tesoros que Herodes le brinda a Salomé a fin de que renuncie a su sanguinaria petición). Atmósfera abigarrada imbuida de poesía, de alabanzas a la belleza del cuerpo y la seducción de las joyas, es decir, al triunfo carnal y al artificio que preside, por otra parte, el astro lunar. La vengativa joven, en un primer plano, está enamorada de Selene, deidad femenina y de la noche:

\section{SALOMÉ}

¡Qué agradable es contemplar la luna! Como una moneda. Como una diminuta flor de plata. Fría y casta. Es virgen, sin la menor duda. Su belleza es virginal. Nadie la ha mancillado. Nunca se ha entregado a los hombres como han hecho otras diosas. (Wilde 18)

La Luna es una diosa que puede simbolizar-y, de hecho, lo hace-las pasiones ocultas, la ambigüedad, la morbosidad dulce de lo prohibido, el lado femenino de toda realidad. Para el paje de 
Herodías, en cambio, con su aspecto amarillento la luna no presagia otra cosa que el advenimiento de una muerte cercana.

\section{EL PAJE DE HERODÍAS}

Contemplad la luna. ¡Qué extraña esta noche! Como una mujer salida de la tumba. Como una mujer muerta. Como si buscara muertos.

También Herodes, que más tarde la ve teñirse de rojo, asigna a la luna un significado de desgracia. Todo ello determina el grado literario-dramático de la obra haciendo que las acciones transcurran en un clima de hipnosis y de magia que desembocará, tras la expresión final de la pasión transgresora, en la muerte.

Es importante destacar que, pese a que Salomé como figura que sirve de eje motor de los acontecimientos tiene cierta relevancia, Wilde hace del viejo tetrarca, no de la princesa hebrea ni de $\mathrm{He}-$ rodías, el personaje central. En él confluyen los contrarios, la rivalidad de designios. Herodes, dotado de una mezcla de volubilidad y fortaleza, manifiesta, como ningún otro personaje, una complejidad de carácter rico en matices psicológicos. Tironeado por fuerzas antagónicas (temor a Dios, deseo sexual inconfesado, respeto, despotismo, irreflexión, etc.), se sumerge en una lucha interna que lo obliga a oscilar entre la palabra jurada y su conciencia, entre la sensualidad y el miedo, entre la soberbia y el sentido del pecado. Por encima de ese litigio íntimo, Herodes, no obstante, permanece invicto; sigue siendo él mismo, incluso al ceder a las sucesivas oleadas de atracción física y de repugnancia espiritual. Al ceder ante el vicio personificado en una resentida Salomé, Herodes, por un lado, exhibe síntomas de debilidad. Ésta no se contenta con dar muerte al hombre que había rechazado sus encantos, sino que, asumiendo hasta el límite las consecuencias de su deletérea voluntad, ejecuta un último acto de pasión necrofílica: obtenida la cabeza de Iokanaán, deposita en ella sus labios impulsada por su amor de vampiro:

\section{SALOME}

No has querido dejarme besar tu boca, Iokanaán. Pues bien, la besaré ahora. La morderé con mis dientes como si fuera un fruto maduro.

Pero al mismo tiempo, Herodes, asqueado ante una conducta que le parece monstruosa, no duda en ordenar la muerte del objeto de sus deseos.

Al final el vicio vence a la virtud, lo pagano al cristianismo. El 
horror se antepone a la renuncia para hacer del episodio bíblico, en su origen relatado con economía de medios, sin mucho lujo de detalles, un cuadro exótico de lujuria, de salvajismo mórbido, de voluptuosidad y de maléfica belleza. Quizás sean esas algunas de las cualidades que expliquen el éxito posterior de la obra, su fascinante encanto. El mismo M. Praz, pese a los reparos que hace al texto, reconoce la enorme fortuna que ha tenido con el paso del tiempo:

En 1896 el drama, originariamente escrito para Sarah Bernhardt-a quien el censor le había impedido representarlo-, tuvo un mediocre éxito en el escenario de l'oeuvre [sic]; en 1901, un año después de la muerte de Wilde, se lo representó en Berlín, y en adelante-gracias también a la música de Richard Strauss - no ha cesado de figurar en los repertorios teatrales europeos. En Alemania se mantuvo en cartel durante un periodo más largo que cualquier otro drama inglés, incluso los de Shakespeare. Fue traducido al checo, al holandés, al griego, al húngaro, al polaco, al ruso, al catalán, al sueco, y hasta al "yiddish".

Y concluye el crítico, no sin cierta ironía: “A las Salomés de Flaubert, de Moreau, de Laforgue y de Mallarmé las conocen sólo los lectores y los exquisitos, pero a la Salomé del genial histrión Wilde todos la conocen" (318).

\section{IV}

Al lado de la popularidad obtenida por la Salomé de Wilde, "El triunfo de Salomé" de Gómez Carrillo, menos afortunado en este sentido, resulta una curiosidad arqueológica. A diferencia del drama de inspiración bíblica, que constituye una obra aislada, sin precedentes ni continuidad dentro de la producción total de su autor y de una carrera literaria proteica surcada por cuentos, poemas, ensayos, comedias, una novela y la conmovedora carta legada a modo de testamento personal, que es el De profundis, el cuento del escritor guatemalteco no ofrece notables singularidades que permitan conferirle una distinción aparte y mayor (tampoco menor) que a otros textos escritos por el mismo autor. Elaborado, sí, en la manera fluida, ágil y musical característica de su estilo, en una prosa que podemos catalogar de artística (según la voluntad estetizante que formularía algunos años más tarde en su ensayo "El arte de trabajar la prosa," de 1905), "El triunfo de Salomé"-frente a otras recreaciones de la misma figura femenina (salidas tal vez de plumas más prestigiosas) - no obtuvo la resonancia necesaria que la haría 
saltar a la posteridad. Lamentablemente, habría que esperar a la labor de rescate de Enrique Marini-Palmieri, que la insertó en su antología de Cuentos modernistas hispanoamericanos (1989), para que el relato de Gómez Carrillo abandonase el olvido en que se hallaba y dejase de ser una más entre cientos y cientos de páginas que en el interior de unos apolillados volúmenes, inencontrables hoy en los circuitos comerciales, duermen el sueño de los justos. El tiempo, podemos observar, al aplicar la inexorable ley de la fugacidad, no ha sido benévolo con este autor, que con el espíritu de sus crónicas divulgó entre sus lectores un cierto estilo de vida frívolo, mundano, "bulevardero." Por otra parte, el olvido en que cayó el nombre de Gómez Carrillo es tanto más injusto si tenemos en cuenta la enorme popularidad de que gozó en su época entre el público lector hispanoamericano, peninsular e incluso en la misma Francia que le dio cobijo y en la que residió desde 1891, si exceptuamos el breve intervalo de dos años (1898-1900) correspondiente con su vuelta a Guatemala. ${ }^{10}$

La revalorización de sus escritos que se ha estado llevando a cabo desde mediados de nuestro siglo hasta la actualidad ha llevado a la crítica especializada a concederle ciertos méritos literarios. Es más: hoy se le considera, junto con Rubén Darío, uno de los mayores propagandistas del modernismo en lengua castellana, a la vez que uno de los mejores artífices en el cultivo de la prosa. Sin embargo, en el aún casi inexplorado océano de sus obras completas pocos son los que se han aventurado a indagar. ${ }^{11}$ Queda todavía mucho terreno que investigar en este sentido. Cuando esa tarea de rescate y examen crítico se haya llevado a cabo, no hay duda de que saldrán a la luz textos como el que aquí estudiamos, "El triunfo de Salomé," y muchos otros, estimables si no siempre por sus cualidades intrínsecas, sí al menos como testimonio y reflejo de los gustos estético-literarios que determinaron las particularidades de una época como la del fin de siglo.

\footnotetext{
${ }^{10}$ Popularidad no siempre implicó simpatía. Un escritor contemporáneo, el argentino Manuel Ugarte, después de colocar a Gómez Carrillo en un puesto elevado entre los grandes escritores iberoamericanos de 1900, pone ciertos reparos a la supuesta frivolidad que emana de su obra: "alguna razón asiste a los que dicen que, después de todo, se justifica el olvido que le va alejando de nosotros, porque a una vida superficial tiene que corresponder un renombre efímero" (133).

${ }^{11}$ Entre los críticos que le han dedicado estudios merece la pena señalar, aparte de los libros de Juan Mendoza, Edelberto Torres y Alfonso Enrique Barrientos, los trabajos parciales de John W. Kronik, Sophia Demetriou, María Luisa Bastos o Francisco Javier Blasco, por sólo citar algunos de los más representativos.
} 
En el año en que se produjo la amistad de Oscar Wilde con Gómez Carrillo (1891) el diplomático y escritor guatemalteco se estaba abriendo camino en el mundo de la prensa periódica en calidad de cronista. Aún no había publicado ningún libro, pues Esquisses, título dado a una colección de crónicas de arte, no aparecería hasta un año después. Aparte de la crónica, "depósito enciclopédico de sabiduría instantánea,” según la definición de Aníbal González (166), que en sus manos adquirió inusitada perfección, hay que recordar que Gómez Carrillo cultivó también la crítica literaria, el ensayo, la literatura de viajes y la novela. Con "El triunfo de Salomé" incursiona además en el género del cuento.

Que Gómez Carrillo, a la hora de elaborar el texto, tuvo en mente la Salomé de Oscar Wilde, lo demuestra la mención que, dentro del mismo relato, hace de su nombre, al lado de otra serie de escritores contemporáneos que desde ángulos distintos habían abordado la misma temática: Mallarmé, Flaubert, Huysmans, Laforgue, Lorrain, "todo lo que las musas decadentes han producido . . durante las postrimerías de nuestro siglo positivista para completar la apoteosis del Pecado" (Gómez Carrillo 110), se cuentan entre las referencias que tuvo a mano. Enrique Gómez Carrillo bebió en estas fuentes diversas, que tuvo en consideración para luego distanciarse de ellas, lo mismo que su joven protagonista, ávida de información cultural con que ambientar mejor la pieza musical que estaba componiendo, devoró textos literarios y obras pictóricas en las que la turbia ambigüedad de la princesa hebrea había quedado inmortalizada. A la lista de testimonios literarios se suma, en efecto, una galería de diversos cuadros-que el narrador enumera con un mal disimulado gesto culturalista-procedentes de épocas distintas (desde el Renacimiento italiano hasta el siglo XIX francés). Las Salomés de Leonardo da Vinci, la de Ticiano, la de Domenico Ghirlandaio, la de Baudry, la de Gustave Moreau, descritas en sintéticas pinceladas, ponen de manifiesto, al quedar acopladas al discurso, el valor estético y el prestigio que da la referencia cultural. Producto de artistas, literatura de la literatura, las obras escritas por los modernistas, ya sean poemas o novelas, ya sean cuentos, crónicas o ensayos, han de aspirar al status artístico, a la privilegiada cima de la estirpe literaria para la que fueron concebidas en un principio. El abrumamiento de la referencia bibliográfica, el culturalismo enciclopedista-excesivos en algunos autores finiseculares-no tenían otra meta que otorgar prestigio a la escritura liberándola de la contingencia a que la condenaba el 
tiempo. ¿Cómo se conseguía (o cómo se pretendía conseguir) ese ambicioso objetivo? Literaturizando la obra pictórica; o lo que es lo mismo, si invertimos la fórmula, pincelando artísticamente el texto escrito, que supera así todo lastre de vulgaridad expresiva, ingresando de ese modo en el inmarcesible reino de la eterna belleza. De ahí la metáfora de la "biblioteca," ligada al interior, y de ahí la metáfora del "museo," destinado a la exhibición, a la mirada externa de un público.

El artificio modernista de citar a autoridades artísticas y literarias, las alusiones intelectuales al mundo de las Bellas Artesy en esto, como en otras cosas, en J. K. Huysmans vieron muchos un pionero ejemplar y paradigmático-no descarta tampoco a la música, que es sentida, por el contrario, como máxima manifestación de sensibilidad creativa. El título del relato de Gómez Carrillo sugiere una autorreferencialidad de contenido: el título del cuento es a su vez el título de la obra musical que compone Marta, exitosa bailarina de veinte años, con la ayuda de su hermano Luciano. El peligro más inmediato que entraña la aglutinación de datos culturales - aparte del elitismo que implica dar por sentado la existencia de un público lector culto, ideal de difícil consecución en una época aquejada de un alto índice de analfabetismo-es que puede entorpecer, a base de frecuentes divagaciones o de comentarios digresivos, el fluir natural de una secuencia narrativa cuyo discurrir puede quedar entonces paralizado de forma repentina. Pero en el relato de Gómez Carrillo no hay temor de que eso suceda. Los contados casos de alarde culturalista-justificados y, por lo demás, nada extensos-que salpican "El triunfo de Salomé" no interrumpen la acción de la historia ni distraen las expectativas que los acontecimientos generan, ya que están perfectamente disueltos entre los elementos internos de la trama.

Integrado en un dialógico juego semiótico e intertextual, el cuento de Gómez Carrillo, en mayor medida que la obra de Wilde, lleva tras sí un acervo cultural más dilatado que, sin duda, tiene en consideración para luego apartarse de él. La tradición queda superada en la figura de Salomé que, tal como aparece aquí, se despoja de toda identidad corpórea. No es Marta, que apenas guarda semejanzas con la diabólica adolescente hebrea. Ésta no representa a la femme fatale; antes bien, es su contrafigura: la "mujer frágil," etérea, de ascendiente prerrafaelita, "alta, delgada, casi incorpórea," una "belleza casi lívida" de "ojos ojerosos," "evocación de un sueño intangible,” se nos dice. Marta está también afectada de una 
enfermedad romántica (la tisis) y condenada por tanto a una desaparición inminente. A la perversa figura bíblica sólo la vincula el don en el arte de bailar, en el que la muchacha madrileña es consumada experta. Quizás tan sólo cuando se la describe bailando en los primeros párrafos del cuento parece suscitar determinadas reminiscencias con la Salomé pintada por Moreau (gasas transparentes, movimientos lentos y ademanes hieráticos, pedrería, orientalismo, símbolos fálicos, . . .). Ahora bien, en realidad ese desdoblamiento dramatizador que se opera en la personalidad de todo intérprete no altera en absoluto su endeble naturaleza ni el hecho de que se muestre vulnerable al extraño influjo de energías maléficas. En efecto, si en el drama de Wilde Salomé ocupa un lugar secundario frente a la figura mucho más interesante del tetrarca Herodes, en el cuento de Gómez Carrillo la mujer sedienta de venganza queda relegada a simple entidad espiritual. Desde este punto de vista Gómez Carrillo va más lejos que el escritor irlandés. Wilde sigue más de cerca el mito antiguo al concebir a una persona de carne y hueso, a una imagen femenina corpórea actuando en el pasado; Gómez Carrillo, situándose en cambio en el presente de su época, desnuda a Salomé de todo atributo material. Salomé es pues una referencia cultural más. Y no sólo eso: es un alma demoníaca que penetra en el cuerpo físico de Marta tiranizando su voluntad hasta destruirla. Por las noches le habla en sueños rememorando lo ocurrido aquel día fatídico en el palacio del tretarca hace dos mil años:

Bailé . . bailé largamente, . . . así . . . muy largamente. Mi cuerpo dorado y ágil plegóse como un junco ante Herodes; luego se enderezó con un movimiento de serpiente; y en cadencia, sacudiendo los collares de mi seno, los brazaletes de mis tobillos, las joyas de mi cintura, todo mi ser se estremeció . . . Mis caderas se estremecieron. El estremecimiento simétrico de mis piernas infantiles y perversas hacían vacilar la voluntad del hombre envejecido... Bailé . . muy largamente.

Otro síntoma de posesión se revela en el momento en que Marta, alentada por un capricho ajeno a su vocación de bailarina, siente la necesidad de escribir la obra musical. Esta obra, en su versión original, tal como la creó Marta, mostraba, antes de que la puliera su hermano, un conjunto desordenado de sonidos que evocaban la lujuria femenina. Digamos que el espíritu atormentado de Salomé impregnaba toda la composición: 
Era un laberinto caótico de notas fantásticamente descabelladas, cuyo conjunto, no obstante, contenía una conmovedora armonía llena de gracia y de incoherencia. Más que una composición, en el sentido artístico de la palabra, era un fárrago de sonidos, una masa inextricable, un follaje enrevesado, algo como una selva virgen en la cual el aura de las mañanas serenas y el rudo viento de las noches invernales produjeran, a veces, cadencias divinamente salvajes.

(107)

Un reencarnacionista pensaría que se trata de una regresión a una vida pasada; mas la situación planteada no se ajusta del todo a la creencia del renacimiento. La joven bailarina no evoca escenas de una existencia anterior; más bien siente que una entidad sobrenatural, invisible, se apodera de su mente. La persona se convierte entonces en el otro individuo, o al menos tiene conciencia de que hay otra personalidad luchando con la suya propia por la ocupación de su cuerpo. Las consecuencias no se hacen esperar. Agotada por tantas jornadas de trabajo, por la pérdida de largas horas de sueño que agudizarían su incurable enfermedad, Marta cae en cama extenuada. El espíritu de Salomé, en efecto, es más fuerte que su naturaleza endeble. El médico le prohibe el mínimo esfuerzo. Transcurren los días sin que se produzca mejoría alguna. En ese estado de convalecencia llega el día del estreno y Marta contempla con tristeza cómo aún no se halla restablecida. Sin embargo, a la hora exacta en que debía comenzar el espectáculo, Marta, lanzada por una fuerza misteriosa, se levanta del lecho e improvisa una danza febril. Una danza de efectos letales, sólo que para la propia ejecutante, no dirigidos hacia ningún espectador.

Quería bailar y bailó. Su torso blanco se crispó con un temblor de agonía; sus piernas largas y finas agitáronse rápidamente; sus caderas vibraron, se contrajeron, se encorvaron, se esponjaron, se desgonzaron con la ligereza vertiginosa de la locura.

Bailó toda la obra en el espacio de algunos minutos. Y luego, extenuada, sin fuerza, sin aliento, perdiendo el equilibrio, cayó en una postrera ondulación, envuelta en un rayo de luna que, para verla, había entrado por la ventana.

Al final la bailarina cae muerta al suelo. La obra ha destruido a su creador. Salomé ha triunfado de nuevo.

Aunque a diferencia de Oscar Wilde, Enrique Gómez Carrillo sí amó a las mujeres-no sólo tenía fama de mujeriego sino que algunas de ellas ocuparon un lugar destacado en su vida (Zoila, 
Aurora Cáceres, Mata Hari, Raquel Meller, Consuelo Suncín, etc.)-, el escritor guatemalteco en su representación de la feminidad maligna, disoluta, no pudo tampoco sustraerse a la visión misógina que desde la valoración del Génesis, que presentaba a Eva como causa del pecado y perdición de Adán, se ha venido transmitiendo secularmente sobre lo que Simone de Beauvoir ha denominado el "segundo sexo" (en el cuento de Gómez Carrillo, añadamos, al estereotipo de Eva-Salomé se contrapone el de María, su perfecta antítesis, simbolizada en la virginal e inocente Marta). Enlazando con las nuevas circunstancias sociales y políticas de la segunda mitad del siglo XIX, que revolucionan el viejo orden y su tradicional distribución de papeles, tanto la creación femenina de Wilde como la de Gómez Carrillo reproducen, bajo su caparazón de entidades ficticias, relegadas al mundo del arte, un discurso ideológico enmascarado que bien podría conectar con la atmósfera de rechazo hacia el sexo femenino latente en sus respectivos entornos sociales (Inglaterra y Francia). Con la irrupción de la New Woman, que poco a poco empezará a intervenir de forma activa en la esfera profesional, política e intelectual (recordemos que a partir de la segunda mitad del siglo XIX aparecen los primeros movimientos feministas organizados), nace en el seno de la sociedad masculina un sentimiento de temor, o lo que es más relevante, un cúmulo de emociones conflictivas, polarizadas, que dentro del lenguaje literario y visual oscilarán entre la fascinación y el aborrecimiento, entre la atracción sexual y el pánico al abismo. La misoginia de finales del XIX, favorecida por el puritanismo burgués, especialmente sexofóbico, pudo desarrollarse bajo las siguientes circunstancias: a) temor del hombre al nuevo papel de la mujer en el trabajo y en la vida pública; b) alarma y desconfianza ante los movimientos feministas; c) relieve y presencia en la sociedad de las prostitutas, cuyo número y extensión se reveló como un fenómeno no sólo inquietante, sino también desconocido hasta la fecha; d) acentuado temor a las enfermedades venéreas, especialmente a la sífilis, que se propagaba alarmantemente como consecuencia de la práctica de las relaciones extramatrimoniales y de la prostitución, y e) influencia de unas teorías de carácter profundamente antifeminista (Schopenhauer, Nietzsche, Nordau, Weininger y Lombroso, entre otros), que intentaron racionalizar y dar "autoridad" socio-filosófica y científica a aquellas reacciones y actitudes masculinas misóginas. Todos esos factores explican la obra de los artistas pertenecientes a los movimientos esteticista y simbolista, quienes, con la especial 
colaboración del decadente finisecular, ofrecieron una peculiar interpretación de la imagen femenina, que dio forma y palabra en la iconoesfera europea de las artes y las letras, precisamente, a aquel tipo de mujer que tanto inquietaba a la sociedad masculina: la mujer artificial (amante-estéril), en detrimento de la mujer natural (esposa-madre).

Salomé, al compartir los rasgos fisonómicos de la primera, en tanto mito primitivo que indaga en el tema de la belleza satánica, mezcla de pasión desenfrenada e instintos sacrílegos, fue recreada como ninguna otra imagen femenina por los artistas de fin de siglo, entre los que se cuentan, al margen de otros que ya hemos señalado en líneas anteriores, Wilde y Gómez Carrillo. Pero ambos escritores no limitaron sus objetivos a la canalización de una retórica misógina (más bien eso fue el resultado de una típica mentalidad de orientación machista subyacente en una sociedad burguesa, de la que, aunque hubieran querido, no hubiesen podido escapar), sino que en otro plano de creación sus visiones de Salomé exteriorizan adecuadamente lo que de irracional anda agazapado en lo más profundo de la mente humana, lo que duerme en nuestro subconsciente. Es una forma de que los aspectos oscuros, vergonzosos, los bajos instintos y deseos reprimidos, por muy malsanos que éstos sean, salgan a la luz sin impedimentos; unas veces desplazando la ordenación "racional" del material historiado hacia el ilogicismo comportamental que exhibe el animal humano, cuya violencia-lo tenemos evidente en el ejemplo wildeano-es siempre "el efecto, no de un cálculo, sino de estados sensibles: la cólera, el miedo, el deseo" (Bataille 91); otras, un espíritu posesivo que al renacer, como el Ave Fénix, de las cenizas del pasado para ejercer de nuevo el mal en un contexto contemporáneo, es el que subvierte el orden de la realidad introduciendo inclusive una percepción sobrenatural. En el cuento de Gómez Carrillo, por ejemplo, de la Salomé real, de su presencia física, sólo quedan los vestigios de un fantasma que sigue cometiendo, eso sí, con igual ímpetu, los mismos viles deseos de antaño. Que ahora la víctima sea otra mujer, alguien del mismo sexo, en vez de un hombre, poco importa. El sentido resultante no varía. Si como asegura Hans Hinterhäuser, "muchas figuras y mitos del Fin de siglo se convierten en una prueba más de que el hombre no puede contentarse a la larga con las dimensiones de lo real, y que la búsqueda de una 'tercera orilla' es una necesidad irreprimible que reside en lo más profundo de su naturaleza (es decir, en su inconsciente)" (120-21), en las Salomés de Wilde y de Gómez Ca- 
rrillo hallamos la ilustración exacta de esas inquietudes. Ambas creaciones se muestran como "símbolos" (en el sentido de C. G. Jung), entre los muchos otros que poseyó el fin de siglo. Exponentes literarios que derivan de la moral machista y burguesa dominante, reflejan las obsesiones masculinas de esa sociedad; prolongan las ramificaciones en el campo de la concepción literaria de lo Eterno Femenino (motivo predilecto); asumen la unión de Eros y Thánatos, la belleza femenina portadora de fatalidad, del mal y de la muerte, y, en última instancia, denotan un hecho indiscutible: que las figuras y mitos (aunque ya desacralizados) de la Antigüedad pueden seguir destilando su fascinante poder creativo sobre la conciencia del hombre moderno.

\section{OBRAS CITADAS}

Allegra, Giovanni. El reino interior. Premisas y semblanzas del modernismo en España. Madrid: Encuentros, 1986.

Barrientos, Alfonso Enrique. Gómez Carrillo, treinta años después. Barcelona: Rumbos, 1959.

Bastos, María Luisa. "La crónica modernista de Enrique Gómez Carrillo o la función de la trivialidad." Relecturas. Estudios de textos hispanoamericanos. Buenos Aires: Librería Hachette, 1989. 51-73.

Bataille, Georges. El erotismo. $5^{a}$ ed. Barcelona: Tustquets, 1988.

Blasco, Francisco Javier. "La imaginación modernista en las crónicas de Gómez Carrillo." A.A.V.V. El modernismo. Renovación de los lenguajes poéticos. Coordinado por Tomás Albaladejo, Javier Blasco y Ricardo de la Fuente. Valladolid: U de Valladolid, 1990. 13-30.

Bornay, Erika. Las hijas de Lilith. Madrid: Cátedra, 1990.

Cansinos Asséns, Rafael. Salomé en la literatura. Madrid: América, 1919.

Darío, Rubén. Autobiografías. Prólogo de Enrique Anderson Imbert. Buenos Aires: Marymar, 1976.

Demetriou, Sophia. "La decadencia y el escritor modernista: Enrique Gómez Carrillo." A.A.V.V. Estudios críticos sobre la prosa modernista hispanoamericana. Ed. José Olivio Jiménez. New York: Eliseo Torres \& Sons, 1975. 223-36.

Ellmann, Richard. Oscar Wilde. Barcelona: Edhasa, 1990.

Gómez Carrillo, Enrique. "El triunfo de Salomé.” A.A.V.V. Cuentos modernistas hispanoamericanos. Ed. Enrique Marini-Palmieri. Madrid: Castalia, 1989. 103-14. 
González, Aníbal. La crónica modernista hispanoamericana. Madrid: José Porrúa Turanzas, 1983.

Hinterhäuser, Hans. Fin de siglo, Figuras y mitos. Madrid: Taurus, 1980.

Huysmans, Joris-Karl. A contrapelo. Ed. Juan Herrero. Madrid: Cátedra, 1984.

Kronik, John W. "Enrique Gómez Carrillo, Francophile Propagandist." Symposium 21 (Spring 1967): 50-60.

Litvak, Lily. El sendero del tigre. Exotismo en la literatura española de finales del siglo XIX (1880-1913). Madrid: Taurus, 1986.

Marini-Palmieri, Enrique. "Enrique Gómez Carrillo." A.A.V.V. Cuentos modernistas hispanoamericanos. Madrid: Castalia, 1989. 101-02.

Mayer, Hans. Historia maldita de la literatura. La mujer, el homosexual, el judío. Madrid: Taurus, 1977.

Mendoza, Juan. Enrique Gómez Carrillo. Estudio crítico-biográfico. Guatemala: Unión Tipográfica Muñoz Plaza, 1940.

Praz, Mario. La carne, la muerte y el diablo en la literatura romántica. Caracas: Monte Ávila, 1970.

Sánchez, Luis Alberto. "Enrique Gómez Carrillo." Escritores representativos de América. $2^{a}$ serie. I. Madrid: Gredos, 1972. 20221.

Torres, Edelberto. Enrique Gómez Carrillo. El cronista errante. Guatemala: Librería Escolar, 1956.

Ugarte, Manuel. "Enrique Gómez Carrillo." Escritores iberoamericanos de 1900. México: Vértice, 1947. 127-39.

Villena, Luis Antonio de. Oscar Wilde. Madrid: Mondadori España, 1989.

Wilde, Oscar y Aubrey Beardsley. Salomé. $2^{a}$ ed. Barcelona: Lumen, 1979. 